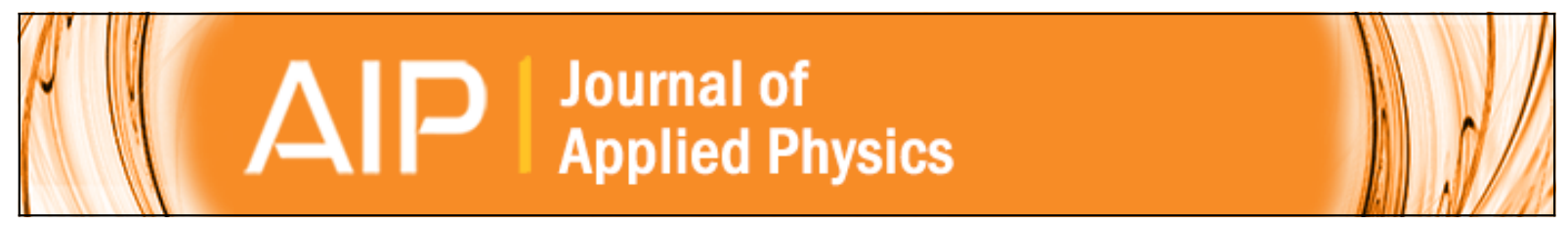

\title{
Electrical isolation of p-type GaAs layers by ion irradiation
}

H. Boudinov, A. V. P. Coelho, and J. P. de Souza

Citation: Journal of Applied Physics 91, 6585 (2002); doi: 10.1063/1.1469693

View online: http://dx.doi.org/10.1063/1.1469693

View Table of Contents: http://scitation.aip.org/content/aip/journal/jap/91/10?ver=pdfcov

Published by the AIP Publishing

\section{AlP Re-register for Table of Content Alerts}

\section{Create a profile. \\ Sign up today!}




\title{
Electrical isolation of $\boldsymbol{p}$-type GaAs layers by ion irradiation
}

\author{
H. Boudinov, A. V. P. Coelho, and J. P. de Souza \\ Instituto de Física, Universidade Federal do Rio Grande do Sul, Porto Alegre, RS, Brazil
}

(Received 6 June 2001; accepted for publication 22 February 2002)

\begin{abstract}
The electrical isolation of $p$-type GaAs layers doped with acceptor impurities incorporated in the $\mathrm{Ga}$ sublattice $(\mathrm{Mg})$ or As sublattice (C) was studied using proton bombardment. It was found that practically the same proton dose is required to reach complete isolation (isolation threshold dose, $\left.D_{t h}\right)$ in layers doped with either $\mathrm{Mg}$ or $\mathrm{C}$ of comparable original sheet hole concentration $\left(p_{s}\right)$. This result is evidence that the sublattice where the acceptor dopant atoms are incorporated does not play any significant role for the isolation formation process in GaAs. The behavior of the recovery of the conductivity during subsequent thermal annealing was found very similar in $\mathrm{Mg}$ and $\mathrm{C}$ doped samples irradiated to equal proton doses. In samples irradiated to doses $<D_{t h}$, the sheet resistance $\left(R_{s}\right)$ increases during annealing at temperatures $>100^{\circ} \mathrm{C}$, reaches a maximum at $\cong 200{ }^{\circ} \mathrm{C}$, and then decreases progressively toward the original value. For proton doses ranging from $D_{t h}$ to $5 D_{t h}$, the isolation is preserved up to the temperature of $\approx 500^{\circ} \mathrm{C}$. The temperature of $\approx 700{ }^{\circ} \mathrm{C}$ was found to be the upper limit for the thermal stability of the isolation in samples irradiated to doses of $100 D_{t h}$. (C) 2002 American Institute of Physics. [DOI: 10.1063/1.1469693]
\end{abstract}

\section{INTRODUCTION}

Compound semiconductors are currently employed in the fabrication of optoelectronic devices and integrated circuits (ICs) for high frequency operation. In addition to these applications, compound semiconductor devices and ICs are especially appropriate for use in harsh environments, such as the outer space where electromagnetic and particle radiation are present.

In group III-V compound semiconductor technology, ion implantation has two major applications, doping and electrical isolation. The latter application is called implantation induced isolation or isolation by ion irradiation. Irradiation with appropriate ion doses is used to convert a conductive layer to a highly resistive one or to improve the isolation between neighbor devices in ICs. It is assumed that the isolation is provided by carrier trapping at deep energy levels in the forbidden band gap associated to the irradiation damage (defect isolation) or to specific impurities used for irradiation (chemical isolation). ${ }^{1,2}$ Since the defect isolation process is much more versatile and simpler than chemical isolation, it is preferred for industrial applications.

Isolation by ion irradiation is normally conducted using light mass ions $\left(\mathrm{H}^{+}, \mathrm{He}^{+}, \mathrm{B}^{+}, \mathrm{O}^{+}\right.$, etc.), since their penetration depths at the energies provided by industrial implanters are satisfactory for the majority of the applications. The doses are generally low $\left(<10^{14} \mathrm{~cm}^{-2}\right)$ because for each ion tens or hundreds of carriers are removed. The active areas of the devices can be easily protected against the ion irradiation by photoresist or dielectric thin films. The degree of electrical isolation after ion irradiation and low temperature annealing $\left(100-500{ }^{\circ} \mathrm{C}\right)$ is even superior to those provided by mesa structures. Furthermore, in contrast to mesa isolation the planarity of the surface is preserved by the ion irradiation. Despite the wide industrial use of isolation by ion irradiation, the physical mechanisms involved with the iso- lation process are not completely understood at present and systematic investigations relating to the isolation of $p$-type GaAs layers have only been sporadically reported in the literature.

In previous studies ${ }^{3}$ we reported on the light ion irradiation of $n$-type GaAs layers. The threshold dose $\left(D_{\mathrm{th}}\right)$, i.e. the lowest dose which converts a conductive layer to a highly resistive one, was found to closely correlate with the estimated number of lattice atom displacements along the depth in the doped layer. We found that the threshold doses are quite similar for irradiation conducted in the temperature range from $-100{ }^{\circ} \mathrm{C}$ to $220^{\circ} \mathrm{C},{ }^{4}$ in spite of the enhanced dynamic annealing in the latter case. Antisite defects created by the replacement collisions and/or their related defect complexes were considered to be carrier trapping centers, by virtue of their low sensitivity to dynamic annealing.

The thermal stability of the electrical isolation of $n$-type layers after irradiation with ${ }^{1} \mathrm{H}^{+},{ }^{4} \mathrm{He}^{+}$, and ${ }^{11} \mathrm{~B}^{+}$has been addressed. ${ }^{5}$ Specific doses and energies were chosen for these ions in order to produce approximately similar damage depth profiles. It was verified that the thermal stability of the isolation depends primarily on the concentration of the irradiation damage and only slightly on the ion mass. The stability of the isolation during post-irradiation thermal annealing increases progressively with the increase of the irradiated dose. For a fixed dose a higher stability of the isolation occurs in samples having a lower original carrier concentration. ${ }^{5,6}$ Fewer investigations have been published regarding the electrical isolation of $p$-type GaAs by ion irradiation. ${ }^{7,8}$ It was verified that the isolation of $n$-type and $p$-type GaAs layers of similar original sheet carrier concentration is attained after implantation of almost identical threshold doses of $\mathrm{H}$ or He ions. ${ }^{8}$ This result was explained assuming that conduction electrons and holes are trapped, respectively, by acceptor and donor centers, these centers being related to $\mathrm{Ga}$ and As antisites. Because the displace- 
ment energies of Ga and As are almost equivalent, ${ }^{9}$ equal concentrations of both antisite defects form in the collision cascades and hence equal concentrations of electron and hole traps are created.

In the present study the isolation and thermal stability of isolation are compared in $p$-type GaAs layers doped with $\mathrm{Mg}$ and $\mathrm{C}$, with acceptor impurities incorporated, respectively, in the $\mathrm{Ga}$ and As sublattices.

\section{EXPERIMENT}

Semi-insulated (SI) LEC GaAs wafers of (100) orientation were used throughout this work. After cleaning, the wafers were implanted at room temperature (RT) at the energy of $900 \mathrm{keV}$ with ${ }^{24} \mathrm{Mg}^{+}$to the dose of $2.5 \times 10^{13} \mathrm{~cm}^{-2}$ (sample I) or with ${ }^{12} \mathrm{C}^{+}$to the dose of $5 \times 10^{13} \mathrm{~cm}^{-2}$ (sample II). The defect annealing and dopant activation were performed by capless (GaAs proximity) rapid thermal annealing (RTA) at $950{ }^{\circ} \mathrm{C}$ for $10 \mathrm{~s}$. From electrical measurements in Van der Pauw devices the sheet resistance $\left(R_{s}\right)$ and sheet hole concentration $\left(p_{s}\right)$ values obtained in sample I are 1.9 $\mathrm{k} \Omega / \mathrm{sq}$ and $2.0 \times 10^{13} \mathrm{~cm}^{-2}$, respectively, corresponding to an electrical activation of $80 \%$ of the implanted $\mathrm{Mg}$ dose. In sample II the $R_{s}$ and $p_{s}$ values are of $7.5 \mathrm{k} \Omega / \mathrm{sq}$ and 1.2 $\times 10^{13} \mathrm{~cm}^{-2}$, respectively. The electrical activation of the implanted C dose was of $24 \%$. Since $\mathrm{C}$ is an amphoteric dopant in $\mathrm{GaAs},{ }^{10}$ one could attribute the low $\mathrm{C}$ activation to a possible acceptor-donor compensation. However, this possibility is disregarded in the present work, since it was shown that the nonelectrically activated fraction of the implanted C dose during RTA remains neutral. ${ }^{11}$ Resistors of rectangular geometry $\left(6 \times 3 \mathrm{~mm}^{2}\right)$ were prepared from cleaved pieces of samples I and II. Ohmic contacts were performed by manually applying In strips $(0.5 \mathrm{~mm}$ wide, $3 \mathrm{~mm}$ long $)$ and sintering at $200^{\circ} \mathrm{C}$ for $2 \mathrm{~min}$. The In strips form mask, which prevent isolation of the underneath contact regions.

The devices were irradiated at RT with ${ }^{1} \mathrm{H}^{+}$at $400 \mathrm{keV}$ to doses in the range of $5.0 \times 10^{10} \mathrm{~cm}^{-2}-2.0 \times 10^{16} \mathrm{~cm}^{-2}$ with ion current density lower than $0.3 \mu \mathrm{A} / \mathrm{cm}^{2}$. The energy of the proton beam was chosen to place the damage peak well beyond the doped layer, such that the damage concentration varies slightly along the depth in the doped layer. In order to minimize channeling effects the device surface normal was tilted by $7^{\circ}$ with respect to beam incidence direction. The $R_{s}$ values during dose accumulation were measured in situ after each dose step. The devices used in the postirradiation annealing study were irradiated by a single dose step. The $R_{s}$ measurements were performed in the dark using a Keithley 617 electrometer.

Post-irradiation annealing cycles were performed in a RTA furnace in the temperature range from 100 to $700^{\circ} \mathrm{C}$, with duration of $60 \mathrm{~s}$ in argon atmosphere. The temperature was measured by a cromel-alumel thermocouple bonded to the sample susceptor and controlled with an accuracy of $\pm 3{ }^{\circ} \mathrm{C}$ by a closed loop control system.

\section{RESULTS AND DISCUSSION}

Figure 1 presents the evolution of the $R_{s}$ during proton dose accumulation in $\mathrm{Mg}$ and $\mathrm{C}$ doped resistors, having simi-

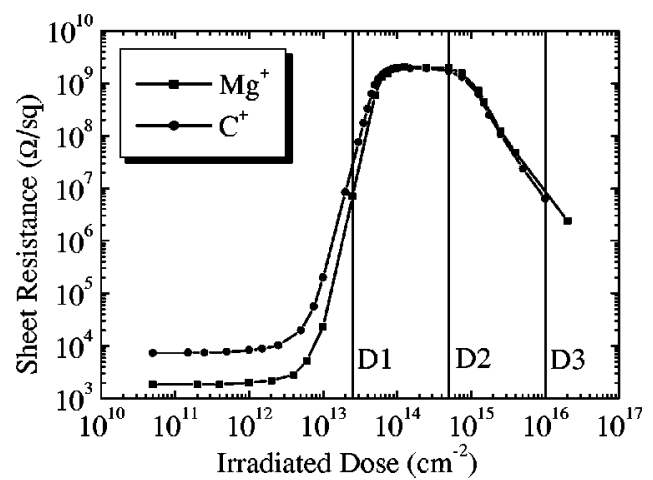

FIG. 1. Evolution of the sheet resistance in $\mathrm{Mg}$ and $\mathrm{C}$ doped $p$-type GaAs resistors during irradiation with $\mathrm{H}^{+}$at $400 \mathrm{keV}$. The doses D1, D2, and D3 used in the thermal stability experiment are shown.

lar hole concentration at the profile peak. The higher initial value of $R_{s}$ in the C doped resistor compared to that in the $\mathrm{Mg}$ doped one is the result of its lower values of $p_{s}$ and effective mobility. During the dose accumulation from 1 $\times 10^{10} \mathrm{~cm}^{-2}$ up to $1 \times 10^{14} \mathrm{~cm}^{-2}$ there is a progressive increase of $R_{S}$ in consequence of carrier trapping and mobility degradation. ${ }^{3,5}$ The dose for which $R_{s}$ just reaches its maximum value $\left(\approx 2 \times 10^{9} \Omega / \square\right)$ corresponds to $D_{t h}$. This maximum value of $R_{s}$ is established by the electrical conduction through the underneath SI GaAs substrate. The accumulation of the dose beyond $D_{t h}$ results in the formation of a plateau in the curves, since all the free carriers were trapped already. The plateau ends when the concentration damage becomes high enough for the onset of intradamage conduction via the hopping mechanism. ${ }^{12}$ After this, the increase of the irradiation dose leads to the increase of hopping conduction and hence to a decrease of $R_{s}$.

It is important to notice that the $D_{t h}$ values obtained in the $\mathrm{Mg}$ and $\mathrm{C}$ doped layers are quite similar. Since $\mathrm{C}$ and $\mathrm{Mg}$ are acceptor dopants incorporated in different sublattices, it is possible to conclude that the physical mechanisms responsible for the isolation formation are not influenced by the dopant sublattice position.

Estimated depth profiles of hole concentration in samples I and II are shown in Fig. 2. The profiles were obtained from the TRIM ${ }^{13}$ simulated implantation profiles after normalization to the total number of electrically activated atoms, assuming uniform activation along the depth. The estimated carrier concentrations at the profile peak in the $\mathrm{Mg}$ and $\mathrm{C}$ doped samples are expected to be similar $(\sim 3$ $\times 10^{17} \mathrm{~cm}^{-2}$ ) and the peak positions approximately coincident $(1.15-1.25 \mu \mathrm{m})$. Included in the figure is the $\mathrm{As}_{\mathrm{Ga}}$ antisite depth profile estimated ${ }^{13}$ for an irradiation to the threshold dose $\left(1 \times 10^{14} \mathrm{~cm}^{-2}\right)$. The region comprising the peak of the carrier profile is the last one to become isolated because of its higher carrier concentration. ${ }^{6}$ Consequently, the minimum dose required to isolate the peak region is the threshold isolation dose, already named $D_{t h}$. One can note in Fig. 2 that the estimated concentration of $\mathrm{As}_{\mathrm{Ga}}$ around the hole peak is approximately 2 times lower than that of hole concentration, in close agreement with what is the expected considering the $\mathrm{As}_{\mathrm{Ga}}$ antisite a double donor center. ${ }^{14}$ 


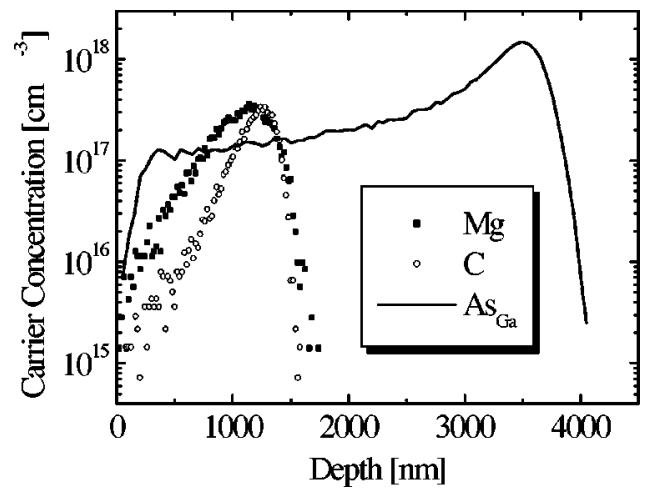

FIG. 2. Estimated carrier profiles in $\mathrm{Mg}$ and $\mathrm{C}$ implanted samples. The $\mathrm{As}_{\mathrm{Ga}}$ profile simulated by TRIM for a dose of irradiation of $1 \times 10^{14} \mathrm{~cm}^{-2}\left(\mathrm{H}^{+}\right.$, $400 \mathrm{keV}$ ) is included.

Thermal stability of the isolation was studied using three different irradiation doses, labeled as D1, D2, and D3 in Fig. 1. In terms of $D_{t h}$ these doses are: D1 $=0.25 D_{t h}, \mathrm{D} 2$ $=5 D_{t h}$, and $\left.\mathrm{D} 3=100 D_{t h}\right)$. After irradiation to the dose D1, the majority of the free carrier was captured by the trapping centers. In the case of D2, all the carriers were captured since the implanted dose is 5 times higher than $D_{t h}$. After irradiation to the dose D3, a significant hopping conduction was established, resulting in a decrease of $R_{s}$ by about two orders of magnitude $\left(R_{s} \cong 10^{7} \Omega / \square\right)$.

The evolution of $R_{s}$ during postirradiation annealing is shown in Figs. 3(a) and 3(b), in samples doped with Mg and $\mathrm{C}$, respectively. For the D1 case, the stability of the isolation

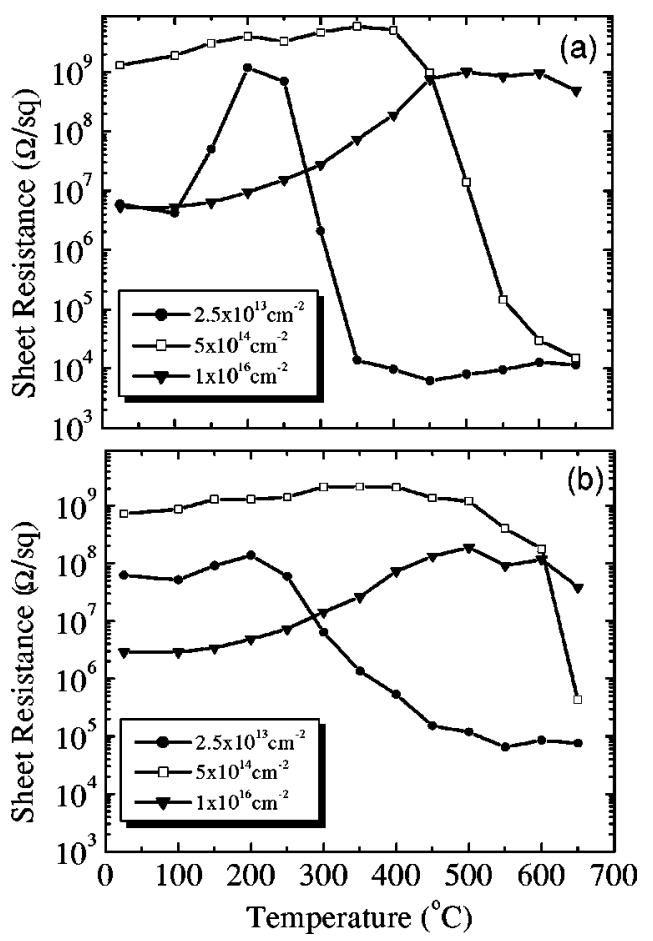

FIG. 3. Evolution of $R_{s}$ with the annealing temperature in $p$-type resistors irradiated with $\mathrm{H}^{+}$at $400 \mathrm{keV}$ and doses $\mathrm{D} 1=0.25 D_{\text {th }}, \mathrm{D} 2=5 D_{\text {th }}$, and $\mathrm{D} 3=100 D_{\text {th }}$ for $\mathrm{Mg}$ (a) and C (b) doped samples. is restricted to temperatures below $250{ }^{\circ} \mathrm{C}$. Above $\approx 250{ }^{\circ} \mathrm{C}$ a decrease of $R_{s}$ by 4-5 orders of magnitude is observed. The increase of the dose from D1 to D2 resulted in remarkable improvements in the thermal stability. In the samples irradiated to the dose $\mathrm{D} 2$ the isolation persists up to the temperature of $450{ }^{\circ} \mathrm{C}$ or $600{ }^{\circ} \mathrm{C}$ in the $\mathrm{Mg}$ or $\mathrm{C}$ doped sample, respectively. The different thermal stability of $\mathrm{Mg}$ and $\mathrm{C}$ doped samples very likely would be attributed to the differences in the thermal behavior of point defects belonging to the As and Ga sublattices. The increase of the irradiation dose to $100 D_{t h}(\mathrm{D} 3)$ leads to the decreasing of $R_{s}$ in consequence of the hopping conduction in the highly damaged region. During postirradiation annealing there is a progressive increase of $R_{S}$ with the increasing of the temperature up to $500^{\circ} \mathrm{C}$, since the carrier hopping becomes less effective as the damage is repaired. The temperature of $\approx 650^{\circ} \mathrm{C}$ is the upper limit for the isolation in samples irradiated to a dose of $100 D_{t h}$.

\section{CONCLUSION}

In summary, carbon and magnesium doped samples were used to study isolation formation and thermal stability after postirradiation annealing in $p$-type GaAs layers. Using $p$-type dopants like $\mathrm{C}$ and $\mathrm{Mg}$, which are incorporated in different GaAs sublattices, the influence of the dopant sublattice position on the isolation formation process was studied. The $\mathrm{As}_{\mathrm{Ga}}$ antisite defects and/or antisite related defect complexes formed in the collision cascades during ion irradiation were considered to be trap centers for the holes. It was determined that the threshold dose for isolation does not depend on the acceptor sublattice position. However, minor differences in the thermal stability behavior were detected between $\mathrm{C}$ and $\mathrm{Mg}$ doped layers.

\section{ACKNOWLEDGMENT}

This work was partially supported by Conselho Nacional de Pesquisas (CNPq).

${ }^{1}$ S. J. Pearton, Mater. Sci. Rep. 4, 313 (1990).

${ }^{2}$ S. J. Pearton, Int. J. Mod. Phys. B 7, 4687 (1993).

${ }^{3}$ J. P. de Souza, I. Danilov, and H. Boudinov, Appl. Phys. Lett. 68, 535 (1996).

${ }^{4}$ J. P. de Souza, I. Danilov, and H. Boudinov, J. Appl. Phys. 84, 4757 (1998).

${ }^{5}$ J. P. de Souza, I. Danilov, and H. Boudinov, J. Appl. Phys. 81, 650 (1997).

${ }^{6}$ J. P. de Souza, I. Danilov, and H. Boudinov, Nucl. Instrum. Methods Phys. Res. B 122, 51 (1997).

${ }^{7}$ F. Ren, S. J. Pearton, C. R. Abernathy, P. W. Wisk, T. R. Fullowan, J. R. Lothian, and R. Esagui, Semicond. Sci. Technol. 8, 605 (1993).

${ }^{8}$ J. P. de Souza, I. Danilov, and H. Boudinov, Radiat. Eff. Defects Solids 147, 109 (1998).

${ }^{9}$ J. W. Corbett and J. C. Bourgoin, in Point Defects in Solids, edited by J. H. Crawford and L. M. Slifkin (Plenum, New York, 1975), p.118.

${ }^{10}$ W. H. van Berlo, J. Appl. Phys. 73, 2765 (1993).

${ }^{11}$ I. Danilov, J. P. de Souza, A. V. Murel, and M. A. A. Pudenzi, Appl. Phys. Lett. 78, 1700 (2001).

${ }^{12}$ Y. Kato, T. Shimada, Y. Shiraki, and K. F. Komatsubara, J. Appl. Phys. 45, 1044 (1974)

${ }^{13}$ J. F. Ziegler, J. P. Biersack, and U. Littmark, in The Stopping and Range of Ions in Solids (Pergamon, Oxford, 1985), Vol. 1.

${ }^{14}$ J. C. Bourgoin, H. J. von Bardeleben, and D. Stievenard, J. Appl. Phys. 64, R65 (1988). 